\title{
Impact response of different materials for sports mouthguards
}

\author{
Maria Moreira, João Carlos Ramos \\ FMUC, Dep. of Dental Medicine, University of Coimbra, Coimbra, Portugal \\ mariamoreira.portugal@gmail.com; \\ joao.ramos@ipmd.pt, bttps:/ /orcid.org/0000-0003-1965-1092
}

Ana Messias, Maria Augusta Neto, Ana Amaro, P.N.B. Reis

University of Coimbra, CEMMPRE, Dep. of Mechanical Engineering, Coimbra, Portugal

ana.messias@uc.pt, bttps://orcid.org/0000-0003-4019-9379

augusta.neto@dem.uc.pt,bttps://orcid.org/0000-0003-3030-0146

ana.amaro@dem.uc.pt, bttps://orcid.org/0000-0001-5237-0773

paulo.reis@dem.uc.pt,bttp://orcid.org/0000-0001-5203-3670

ABSTRACT. Up to this moment, there is no guideline regarding the materials to produce mouthguards. The most used is Ethylene-Vinyl Acetate (EVA). Studies indicate that laminating EVA sheets with rigid components could increase the protection capacities of the mouthguards. On the other hand, other studies suggest that only replacement of the material within its structure can increase energy absorption. Therefore, this work aims to evaluate the impact response of four different foils when compared to a $4 \mathrm{~mm}$ thickness EVA sheet. Five different materials were subjected to impact tests with energies of $1.72 \mathrm{~J}, 2.85 \mathrm{~J}$ and $4.40 \mathrm{~J}$. In this context was considered the following materials: EVA foils (G1), EVA foils with an EVA foam core (G2), EVA foils with an acetate core (G3), Foils of Erkoloc-pro (G4) and Foils of Ortho IBT resin (G5). Comparisons between the materials were made by qualitative analysis of the average energy-time and load-displacement curves, as well as by comparison of the peak load, maximum displacement, contact time and absorbed energy using the Kruskal-Wallis test. It was possible to conclude that statistically significant differences were found in the energy absorbed $(p=0.001)$. Laminated foils with a soft core $(G 2)$ are a good option to produce mouthguards, while EVA foils with an acetate core (G3) and foils of Ortho IBT resin (G5) were declared unsuitable.

KEYWORDS. Mouthguard; Impact response; Thermoforming foil; Mechanical testing.

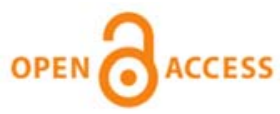

Citation: Moreira, M., Ramos, J.C., Messias, A., Neto, M. A., Amaro, A., Reis, P.N.B., Impact response of different materials for sports mouthguards, Frattura ed Integrità Strutturale, 57 (2021) 63-69.

Received: 29.04.2021

Accepted: 13.05.2021

Published: 01.07.2021

Copyright: (C) 2021 This is an open access article under the terms of the CC-BY 4.0, which permits unrestricted use, distribution, and reproduction in any medium, provided the original author and source are credited. 


\section{INTRODUCTION}

$\mathrm{I}$ $\mathrm{t}$ is known that collision or contact sports and some recreational activities can expose practitioners to harmful impacts in the orofacial region, with the associated risk of injury. Despite the current call for prevention in the health area, studies developed by Green [1] and Knapik et al. [2] reveal that the incidence and prevalence of orofacial lesions tend to increase. Bourguignon and Sigurdsson [3] estimated, for example, that $14 \%$ to $25 \%$ of children, adolescents and young adults can be the target of at least one traumatic episode in their lifetime. Therefore, in particular, athletes who practice collision or contact sports are advised to use safety devices, such as mouthguards, to minimize the risk of traumatic injuries. Several authors even claim that properly adjusted mouthguard reduces the incidence of orofacial injuries in sports [4-6]. For this purpose, there are three types of mouthguards: Ready-Made or Stock Mouth guard; the Mouth-Formed "Boil-AndBite" and the Custom-Fitted Mouth guard, which is considered the best protection for teeth, lips and jaw, because it is done by a dentist or dental technician and can be adapted to the athlete's mouth [7]. According to Bastian et al. [8] the boil andbite mouthguards were the most recommended by orthodontists. However, most patients who used these mouthguards reported forgetfulness as the most frequent reason for not always using them due to the discomfort created. On the other hand, some athletes do not use mouthguards because they consider that it affects performance and promotes some discomfort [9], but Ferreira et al. [10] clarify that mouthguards do not impair the athlete's performance.

According to American Dentistry Association Council (see https://www.ada.org/en/member-center/oral-healthtopics/mouthguards), a mouthguard should not only protect teeth and surrounding structures but also prevent ingestion or inhalation in case of loss or fractured teeth. Also, it must be made of resilient materials able to dissipate the forces applied during an impact and to reduce the deflection transmitted to the underlying structures. The open literature $[1,3,11,12]$ also reports that such devices should be psychologically and physically comfortable for the patient. However, up to this moment, there is no guideline regarding the materials to produce mouthguards, but Green [1] and Fukasawa et al. [13] indicate that Ethylene-Vinyl Acetate (EVA), a thermoplastic co-polymer, is the most used material in these components. Nevertheless, the higher vinyl acetate content promotes greater flexibility for EVA foils, which is reflected in lower stiffness and hardness. On the other hand, higher damping capacity and, consequently, better energy absorption.

In this context, Knapik et al. [2] report that, although latex rubber was a material widely used in the first mouthguards, it has less shock absorption, less hardness and less tear and tensile strength than EVA or polyurethane. Kadota et al. [14] use mouthguards with $3 \mathrm{~mm}$ of EVA to protect weak periodontal tissue of children, in which the thickness of the sheet is considered a determining factor for the reduction of the external force to teeth. However, for Westerman et al. [15] this minimum thickness must be between 3 and $4 \mathrm{~mm}$ to absorb energy and reduce the forces transmitted when impacted. These authors also mention that there is an inverse proportion between the shock absorption capacities and the thickness of the mouthguard. Nevertheless, according to Australian Dental Association, a minimum thickness of $4 \mathrm{~mm}$ is required for the labial flange of a mouthguard. Moreira et al. [16] developed studies using a custom-made mouthguard produced by the Erkoform 3D Motion with the Occluform-3 accessory considering two plaques of ethyl vinyl acetate $4 \mathrm{~mm}$ and $2 \mathrm{~mm}$ thick and found that there were no statically significant differences concerning the retention parameters. On the other hand, Takeda et al. [17] and Lunt et al. [18] report that higher values of thickness for mouthguards improve the protection because they increase the absorbed energy, but excessive thicknesses impair the athletes' comfort and performance. Consequently, it compromises the use of mouthguards in critical situations. Besides that, Lunt et al. [18] concluded that only the combination of different materials, EVA with rigid laminates sandwiches and/or additional air spacing, is possible to promote significant improvements in the level of protection.

EVA polymeric foams have gained increasing importance due to a unique combination of properties, such as good damping performance, lightness, good ageing, chemical resistance and inertness. In this context, the open literature reports significant benefits in terms of absorbed energy when air cells are introduced within the EVA sheet thickness or with the addition of foaming agents $[1,3,13,19]$. However, the main disadvantage of the current standard of production of customized mouthguards is the fabrication process that requires two appointments - one for impression-taking and another for insertion and athlete instruction - and implies wasting the excess of the material, increasing the associated costs. 3D printing could be the solution to overcome this limitation. New materials with shore A hardness similar to that of EVA foils have become available and could be useful to produce mouthguards, guaranteeing the required precision and preventing material waste $[1,2]$.

Although all options have been widely used in other sports or even in the development of passive safety mats for athletes, from a scientific point of view, there are still few studies regarding the mechanical characterization of these materials for application in mouthguards. Therefore, this study intends to evaluate the response to the impact of five materials to obtain an architecture with better performance. In this context, it can replace the conventional EVA in mouthguards. For this 
purpose, the following materials will be considered: EVA foils, EVA foils with an EVA foam core, EVA foils with an acetate core, Foils of Erkoloc-pro and Foils of Ortho IBT resin. Impact tests were carried out with energies of $1.72 \mathrm{~J}$, $2.85 \mathrm{~J}$ and $4.40 \mathrm{~J}$, and the results compared with those obtained with EVA.

\section{EXPERIMENTAL PROCEDURE}

$\mathrm{F}$ ive groups of thermoforming foils, conveniently described in Tab. 1, were prepared to perform low velocity impact tests by drop-weight. The first group used EVA, considered a generic foil with a vinyl acetate ratio $<0.3 \%$ and Shore A 82 hardness. For the EVA_SOFT and EVA_HARD groups, laminated foils were produced using a hot press machine and by the moulding technique. Erkoloc-pro foils (with the hard side of PETG and the soft side of TPU) from Erkodent ${ }^{\mathbb{B}}$ with $3 \mathrm{~mm}$ were used in the ERKOLOC group. Finally, in the RESIN_IBT group, the foils were printed on the NextDent ${ }^{\mathrm{TM}} 5100$ 3D printer. The chosen material was NextDent Indirect Bonding Tray (Ortho IBT), a monomer based on acrylic esters with Shore A hardness similar to EVA.

\begin{tabular}{|c|c|c|c|}
\hline & Group/Material & Thickness & Structure \\
\hline EVA & EVA & $4 \mathrm{~mm}$ & 58 \\
\hline EVA_SOFT & $\mathrm{EVA}+\mathrm{EVA}$ foam & $\begin{array}{l}1.5 \mathrm{~mm} \mathrm{EVA}+2 \mathrm{~mm} \text { EVA } \\
\text { foam }+1.5 \mathrm{~mm} \text { EVA }\end{array}$ & \\
\hline EVA_HARD & $\mathrm{EVA}+$ Acetate & $\begin{array}{l}2 \mathrm{~mm} \text { EVA }+0.5 \mathrm{~mm} \\
\text { acetate }+2 \mathrm{~mm} \mathrm{EVA}\end{array}$ & 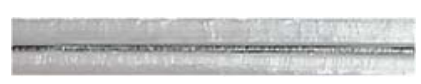 \\
\hline ERKOLOC & $\begin{array}{l}\text { PETG co-polyester }+ \text { Therm. } \\
\text { polyurethane }\end{array}$ & $2 \mathrm{~mm}$ PETG+1 mm TPU & 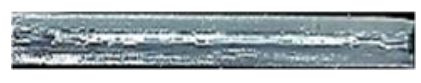 \\
\hline RESIN_IBT & $\begin{array}{l}\text { Aliphatic Urethane Acrylate } \\
\text { Oligomer }\end{array}$ & $4 \mathrm{~mm}$ & \\
\hline
\end{tabular}

Table 1: Materials analysed in this study.

The low velocity impact tests were carried out using a drop weight-testing machine Instron-Ceast 9340. A $10 \mathrm{~mm}$ diameter impactor with a mass of $3.4 \mathrm{~kg}$ was used. The test was performed on circular section samples of $55 \mathrm{~mm}$ and the impactor strokes at the center of the samples obtained by centrally supporting the 120x120 [mm] samples. Impact energies of $1.72 \mathrm{~J}$, $2.85 \mathrm{~J}$ and $4.40 \mathrm{~J}$ were applied, which correspond to impact velocities of $1 \mathrm{~ms}^{-1}, 1.29 \mathrm{~ms}^{-1}$ and $1.61 \mathrm{~ms}^{-1}$, respectively. The tests were carried out at room temperature and, for each group/condition, five specimens were tested.

Finally, comparisons between mouthguard materials were made by qualitative analysis of the average energy-time and loaddisplacement curves, as well as by comparison of the peak load $(\mathrm{N})$, maximum displacement (mm), impact time (ms) and absorbed energy (J) using the Kruskal-Wallis test.

\section{RESULTS AND DISCUSSION}

$\mathrm{F}$ rom the impact tests carried out, Fig. 1 shows the typical curves obtained for all materials tested for the impact energy of $4.4 \mathrm{~J}$. However, the profile of these curves is representative of all others obtained for $1.72 \mathrm{~J}$ and $2.85 \mathrm{~J}$. However, it is noted higher energies than 4.4 J for EVA and EVA_Soft, which are a consequence of these materials' mechanical properties. In fact, the plates produced with these materials have a very elastic behaviour. Consequently, the displacement is superior, producing, in this case, higher energy values.

Fig. 1a) shows typical energy-time curves, which show that the impact energy was not high enough to promote full penetration, because the impactor sticks into specimens and rebound always. The beginning of the plateau is coincident with the loss of contact between the striker and the specimen. Hence, this energy coincides with the absorbed energy by the 
specimen $[20,21]$. Therefore, the difference between this energy and the energy at peak load is the elastic energy. On the other hand, Fig. 1b) shows typical load-displacement curves, where it is possible to observe that the load increases up to a maximum value $\left(\mathrm{P}_{\max }\right)$ followed by a drop after the peak load. This drop is due to the loss of contact between the striker and specimen. During unloading it is possible to see the influence of the different foils structure.

Based on the results obtained in these tests, Tab. 2 presents the maximum load, maximum displacement, contact time and absorbed energy, in terms of average values and standard deviation for all materials. A statistical analysis was also performed resorting to IBM SPSS ${ }^{\circledR}$ Statistics version 23. Group comparisons were made with the Kruskal-Wallis test and all post-hoc comparisons considering Bonferroni correction. The significance level was set at 0.05 . Statistically significant differences were found in the energy absorbed $(\mathrm{p}=0.001)$, regardless of the impact energy.
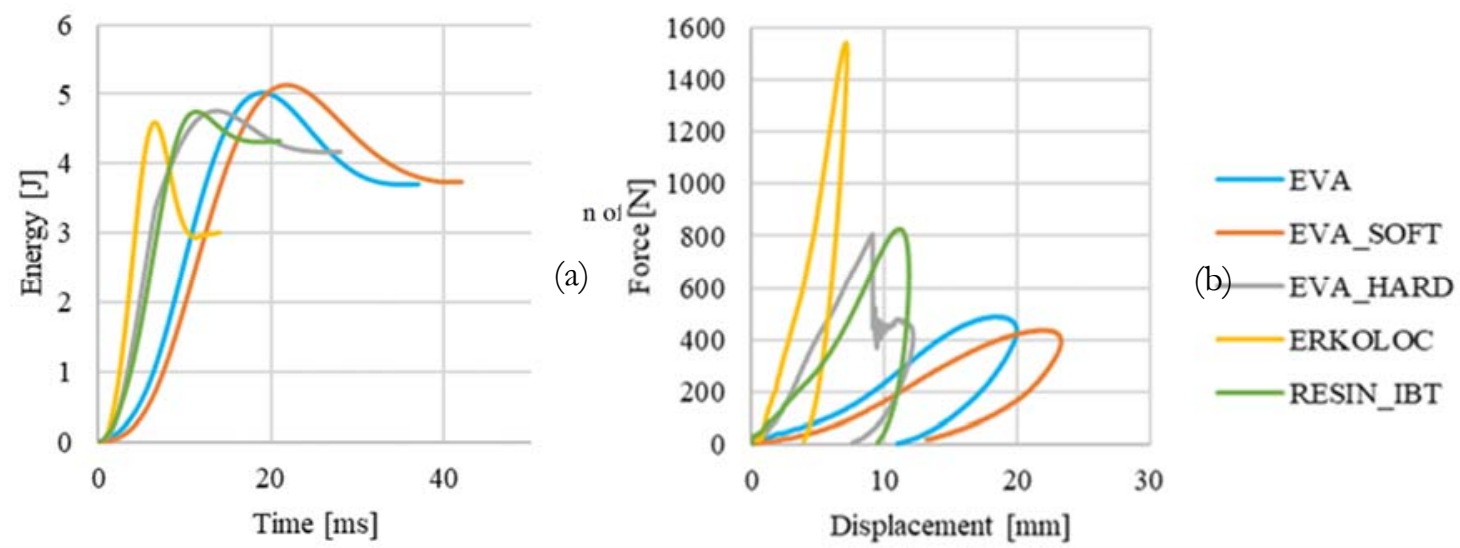

Figure 1: For all materials, typical: a) energy versus time curves; b) load versus displacement curves.

\begin{tabular}{lcccc}
\hline Group/Material & Peak Load [N] & Max Displacement $[\mathrm{mm}]$ & Contact time [ms] & Absorbed energy []] \\
EVA & $511.8( \pm 25.6)^{\mathrm{a}}$ & $20.1( \pm 0.6)^{\mathrm{a}}$ & $18.8( \pm 0.5)^{\mathrm{a}}$ & $3.5( \pm 0.3)$ \\
EVA_SOFT & $455.5( \pm 10.5)^{\mathrm{b}, \mathrm{c}}$ & $23.2( \pm 0.8)^{\mathrm{b}}$ & $21.4( \pm 0.5)^{\mathrm{b}, \mathrm{c}}$ & $3.5( \pm 0.2)$ \\
EVA_HARD & $858.3( \pm 32.4)^{\mathrm{c}}$ & $11.9( \pm 0.6)$ & $12.7( \pm 0.6)^{\mathrm{b}}$ & $4.1( \pm 0.1)^{\mathrm{a}}$ \\
ERKOLOC & $1549( \pm 24.9)^{\mathrm{a}, \mathrm{b}}$ & $7.2( \pm 0.1)^{\mathrm{a}, \mathrm{b}}$ & $6.5( \pm 0.1)$ & $2.9( \pm 0.2)^{\mathrm{a}, \mathrm{b}}$ \\
RESIN_IBT & $796.2( \pm 51.3)$ & $11.9( \pm 0.9)$ & $11.7( \pm 0.9)^{\mathrm{c}}$ & $4.4( \pm 0.1)^{\mathrm{b}}$ \\
P & $<0.001^{*}$ & $<0.001^{*}$ & $<0.001^{*}$ & $<0.001^{*}$ \\
\hline
\end{tabular}

Values represent average $( \pm$ ) standard deviation. Similar superscript letters indicate groups that present statistically significant differences at the 0.05 level.

Table 2: Average values of the peak load, maximum displacement, and elastic recuperation at impacts of $4.4 \mathrm{~J}$

Pairwise comparisons indicate that EVA_SOFT is statistically superior to ERKOLOC regarding maximum displacement $(p=0.006$ and $p<0.001$, respectively) and contact time ( $p=0.006$ and $p<0.001$, respectively). The EVA_SOFT group simultaneously presented the highest contact time and the lowest values of peak impact load. As reported by Verdejo and Mills [22] and Mocian et al. [23], soft damping systems, like this laminated foil, tend to increase the contact time of impacts and, consequently, spread energy over a larger area, decreasing the damage in a local area. ERKOLOC presents a mean peak impact force, statistically superior to EVA $(p=0.017)$ and EVA_SOFT $(p<0.001)$. EVA_HARD and RESIN_IBT presents the higher energy absorption by the impactor statistically superior to ERKOLOC ( $\mathrm{E}=0.001$ and $\mathrm{p}<0.001$, respectively). From Tab. 2, for example, it is possible to find an increase of about 41.4\% in the absorbed energy when the EVA_HARD material is compared with Erkoloc, but in terms of maximum load there is a decrease around $44.6 \%$.

This evidence can be reported in Fig. 2, where is shown the impact damage observed on all materials with $4.4 \mathrm{~J}$ impact. A close observation of the contact area of the impactor reveals barely noticeable permanent deformation in EVA (a) and EVA_SOFT (b) foils. EVA_HARD (c) foils were perforated and showed a wide area of delamination surrounding the impact. ERKOLOC $(\mathrm{d})$ showed the narrowest area of contact associated with puncture type permanent association. Though no permanent deformation was visible on the surface of RESIN_IBT (e) it was clear that the foil fractured. 
Finally, Tab. 3 presents the restored energy for all materials and the impact energies to compare the impact performance in a wider range of energies. Of all the tested materials, it is possible to verify that the ones that presented the highest restored energy were EVA and Erkolock. Therefore, when comparing them, it appears that for the lowest impact energy (1.72 J) Erkoloc presents a restored energy around 7.5\% lower than that obtained with EVA. However, when the impact energy increases, the restored energy obtained with the Erkolock material is higher than the values observed with EVA. In this case, compared to EVA, increases of around $9.7 \%$ and $26.7 \%$ were observed for Erkolock, respectively, for impact energies of $2.85 \mathrm{~J}$ and $4.4 \mathrm{~J}$. Therefore, for higher energies, Erkoloc shows more tendency to restore energy after impact. On the other hand, it is noticed that for the impact energy of 4.4 J, EVA_SOFT was the second material that presented the highest restored energy, which means that these foils have a good impact absorption capacity for impacts with high energy levels. These results are in good agreement with those obtained by Mocian et al. [24].

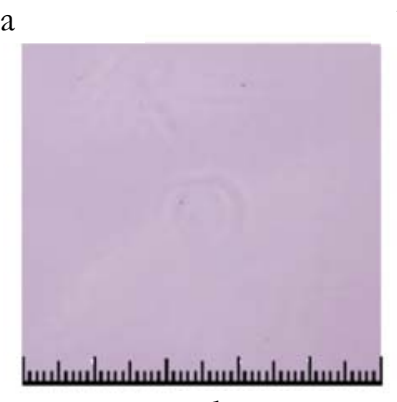

d b

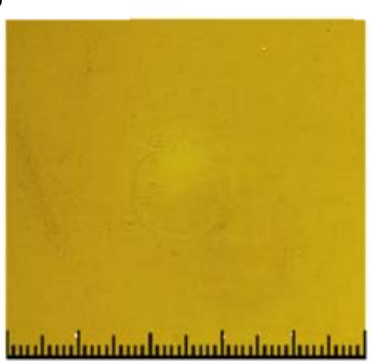

e
C
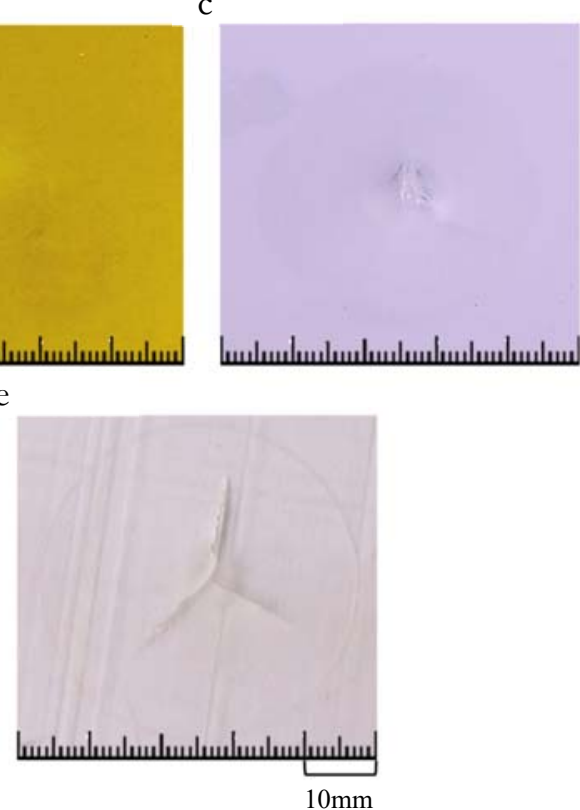

Figure 2: Impact damages observed for an impact energy of 4.4 J and for: (a) EVA; (b) EVA_SOFT; (c) EVA_HARD; (d) ERKOLOC; (e) RESIN_IBT.

\begin{tabular}{cccccc}
\hline & \multicolumn{5}{c}{ Restored energy [\%] } \\
Impact Energy J] & EVA & EVA_SOFT & EVA_HARD & ERKOLOC & RESIN_IBT \\
1.72 & $53.4( \pm 6.4)$ & $31.5( \pm 3.4)$ & $28.0( \pm 2.0)$ & $48.6( \pm 3.4)$ & $7.3( \pm 0.9)$ \\
2.85 & $41.4( \pm 6.3)$ & $25.6( \pm 5.1)$ & $23.0( \pm 3.7)$ & $45.0( \pm 0.7)$ & $11.3( \pm 1.1)$ \\
4.4 & $30.2( \pm 6.5)$ & $31.8( \pm 3.9)$ & $14.4( \pm 2.3)$ & $37.8( \pm 3.3)$ & $7.3( \pm 0.8)$ \\
\hline
\end{tabular}

Table 3: Restored energy obtained for all materials and impact energies.

Possible mechanical improvements in hard layers or their inserts in mouthguards materials have also been studied. In this case, when the impact energy increases, the sheet is perforated, which means that the energy is higher than the material can absorb. In fact, only very small amounts of energy are absorbed in these cases. Although acetate presents adequate energy absorption under low impact energies, delamination of the foil was observed experimentally, which makes this material unsafe because, in these conditions, the peak load is transmitted to the oral structures. Green [1], Takeda et al. [25] and Westerman et al. [26] also showed that sandwiching hard layers with softer EVA did not improve shock absorption ability. In the present study, this phenomenon occurred with an impact energy of $4.4 \mathrm{~J}$ in EVA_HARD material. 
Regarding the Erkoloc-pro foils, they contain polyester and thermoplastic polyurethane (TPU). These foils have high stability, biocompatibility, good elastomeric properties, good resistance to fatigue loads and low water absorption. For this study, $3 \mathrm{~mm}$ foils were chosen. Materials that had higher impact loads (as seen on Fig. 1), like ERKOLOC, correspond to more brittle materials. The load, in these cases, drops suddenly because of the damage and the material is severely punctured. Lower impact load values indicate less impact shock and, therefore, impact attenuation, as reported by Mocian et al. [23], Westerman et al. [26] and Alexandra et al. [27]. Although delamination didn't happen, the lower part of the skin was damaged with impacts of $4.4 \mathrm{~J}$. These findings are corroborated by the level of penetration seen in Fig. 2.

3D printing is becoming popular among clinicians. Mcglumphy et al. [28] and Liang et al. [29], for example, agree that the possibility of reducing material waste, costs and improve accuracy make this technology attractive. The material used in this study, Ortho Resin IBT, is a monomer based on acrylic esters, and its selection was based on a hardness shore similar to EVA (A 85). Therefore, from Tabs. 2 and 3, it is possible to conclude that RESIN_IBT is the material with the highest absorbed energy and, consequently, the material with the lowest restored energy (elastic energy). Similar to the study developed by Mocian et al. [24], these results indicate that this material has a weak damping capacity. Although no delamination is observed, it is noticed a cohesive fracture of the foil. According to the authors' best knowledge, there are no data available in the literature for comparison.

\section{CONCLUSIONS}

I $\mathrm{t}$ was found that the insertion of an intermediate layer with less stiffness than EVA (EVA_SOFT) is a good option to produce customized mouthguards, taking into account its high values of displacement. Rigid and thinner materials (ERKOLOC) were found to be unsuitable due to the damage associated, even though they exhibit high levels of elastic energy. It was also found that thermoformed foils made with semi-rigid core using acetate suffer delamination and, as the three-dimensionally printed materials used in this study, are not suitable for the production of mouthguards. It is important to consider that other materials might suit as semi-rigid core and may not suffer delamination, which would make them suitable for this purpose.

\section{ACKNOWLEDGEMENTS}

This research is sponsored by FEDER funds through the program COMPETE - Programa Operacional Factores de Competitividade - and by national funds through FCT - Fundação para a Ciência e a Tecnologia -, under the project $\mathrm{UIDB} / 00285 / 2020$.

\section{REFERENCES}

[1] Green, J.I. (2017) The Role of Mouthguards in Preventing and Reducing Sports-related Trauma, Prim. Dent. J., 6, pp. 27-34. DOI: $10.1308 / 205016817821281738$.

[2] Knapik, J.J., Marshall, S.W., Lee, R.B., Darakjy, S.S., Jones, S.B., Mitchener, T.A., Cruz, G.G., Jones, B.H. (2007) Mouthguards in sport activities: history, physical properties and injury prevention effectiveness, Sport Med. 37, pp. 117-144. DOI: 10.2165/00007256-200737020-00003.

[3] Bourguignon, C., Sigurdsson, A. (2009) Preventive Strategies for Traumatic Dental Injuries. Dent. Clin. North Am. 53, pp. 729-749. DOI: $10.1016 /$ j.cden.2009.06.002.

[4] Kang, Y., Franco, C.S. (2014) A story of dental injury and orthodontics. Oral Health Dent. Manag. 13, pp. 243-253. DOI: $10.4172 / 2247-2452.1000572$.

[5] Labella, C.R., Smith, B.W., Sigurdsson, A. (2002) Effect of mouthguards on dental injuries and concussions in college basketball. Med. Sci. Sports Exerc. 34, pp.41-44.

[6] Lieger, O., Von Arx, T. (2006) Orofacial/cerebral injuries and the use of mouthguards by professional athletes in Switzerland. Dent. Traumatol. 22, pp. 1-6. DOI: 10.1111/j.1600-9657.2006.00328.x.

[7] Pawar, P.G., Suryawanshi, M.M., Patil, A.K., Purnale, P.S., Ali, F.M. (2013) Importance of mouth guards in sports: a review. J. Evol. Med. Dent. Sci. 2pp. 8903-8908. DOI: 10.14260/jemds/1546. 
[8] Bastian, N.E., Heaton, L.J., Capote, R.T., Wan, Q., Riedy, C.A., Ramsay, D.S. (2020) Mouthguards during orthodontic treatment: Perspectives of orthodontists and a survey of orthodontic patients playing school-sponsored basketball and football. Am. J. Orthodo. Dentofacial Orthop. 157, pp. 516-525.e2. DOI: 10.1016/j.ajodo.2019.04.034.

[9] Ahmed, I., Fine. P. (2021) Injury prevention versus performance: has the time come to mandate the use of mouthguards in all contact sports? BMJ Open Sport Exerc. Med. 7, pp. e000828. DOI: 10.1136/bmjsem-2020-000828.

[10] Ferreira, G.B., Guimarães, L.S., Fernandes, C.P., Dias, R.B., Coto, N.P., Antunes, L.A.A., Antunes, L.S. (2019) Is there enough evidence that mouthguards do not affect athletic performance? A systematic literature review. Int. Dent. J. 69, pp. 25-34. DOI: $10.1111 /$ idj.12406.

[11] Bochnig, M.S., Oh, M.J., Nagel, T., Ziegler, F., Jost-Brinkmann, P.G. (2017) Comparison of the shock absorption capacities of different mouthguards. Dent. Traumatol. 33, pp. 205-213. DOI: 10.1111/edt.12324.

[12] Parker, K., Marlow, B., Patel, N., Gill, D.S. (2017) A review of mouthguards: Effectiveness, types, characteristics and indications for use. Br. Dent. J. 222, pp. 629-633. DOI: 10.1038/sj.bdj.2017.365.

[13] Fukasawa, S., Churei, H., Chowdhury, R.U., Shirako, T., Shahrin, S., Shrestha, A., Wada, T., Uo, M., Takahashi, H., Ueno, T. (2016) Difference among shock-absorbing capabilities of mouthguard materials. Dent. Traumatol. 32, pp. 474-479. DOI: $10.1111 /$ edt.12275.

[14] Kadota, T., Okawa, R., Otsugu, M., Ohata, J., Hanaoka, I. Nakano, K. (2021) Mouthguards for a childhood hypophosphatasia patient to protect periodontal tissue of immature permanent teeth-Case report. Pediatr. Dent. J. 31, pp. 117-122. DOI: $10.1016 /$ j.pdj.2021.01.004.

[15] Westerman, B., Stringfellow, P.M., Eccleston. J.A. (2002) EVA mouthguard: how thickness should they be? Dent Traumatol. 18, pp. 24-27. DOI: 10.1034/j.1600-9657.2002.180103.x.

[16] Moreira, A., Mendes, J., Fonte, E., Ferreira, D., Clemente, M., Vasconcelos, M. (2019) Implementation of a custommade mouthguard in a professional basketball team. Journal of Mechanical Engineering and Biomechanics 3, pp. 2532. DOI: $10.24243 / \mathrm{JMEB} / 3.4 .195$.

[17] Takeda, T., Ishigami, K., Jun, H., Nakajima, K., Shimada, A., Ogawa, T. (2004) The influence of the sensor type on the measured impact absorption of mouthguard material. Dent. Traumatol. 2004, pp. 29-35.

DOI: $10.1111 /$ j.1600-4469.2004.00220.x.

[18] Lunt, D.R., Mendel, D.A., Brantley, W.A., Beck F.M., Huja, S., Schriever, S.D., Grentzer, T.H., Alapati, S.B. (2010) Impact energy absorption of three mouthguard materials in three environments. Dent. Traumatol. 26, pp. 23-29. DOI: $10.1111 /$ j.1600-9657.2009.00848.x.

[19] Genina, N., Holländer, J., Jukarainen, H., Mäkilä, E., Salonen, J., Sandler, (2016) N. Ethylene vinyl acetate (EVA) as a new drug carrier for 3D printed medical drug delivery devices. Eur. J. Pharm. Sci. 90, pp. 53-63.

DOI: 10.1016/j.ejps.2015.11.005.

[20] Aktas, M., Atas, C., Icten, B.M., Karakuzu, R. (2009) An experimental investigation of the impact response of composite laminates, Compos. Struct., 87, pp. 307-13. DOI: 10.1016/j.compstruct.2008.02.003.

[21] Reis, P.N.B., Ferreira, J.A.M., Santos, P., Richardson, M.O.W., Santos, J.B. (2012). Impact response of Kevlar composites with filled epoxy matrix, Compos. Struct., 94, pp. 3520-8. DOI: 10.1016/j.compstruct.2012.05.025.

[22] Verdejo, R., Mills, N.J. (2004) Heel-shoe interactions and the durability of EVA foam running-shoe midsoles. J. Biomech. 37, pp. 1379-1386. DOI: 10.1016/j.jbiomech.2003.12.022.

[23] Mocian, O., Constantinescu, D.M., Sandu, M., Sorohan, Ş. (2017) Impact response of polyurethane and polystyrene sandwich panels. Procedia Struct. Integr. 5, pp. 653-658. DOI: 10.1016/j.prostr.2017.07.035.

[24] Mocian, O.A., Constantinescu, D.M., Sorohan, Ş., Sandu, M. (2019) Low velocity failure and integrity assessment of foam core sandwich panels. Frat. ed Integrita Strutt. 13, pp. 230-241. DOI: 10.3221/IGF-ESIS.48.24.

[25] Takeda, T., Ishigami, K., Handa, J., Naitoh, K., Kurokawa, K., Shibusawa, M., Nakajima, K., Kawamura, S. (2006) Does hard insertion and space improve shock absorption ability of mouthguard? Dent. Traumatol. 22, pp. 77-82. DOI: 10.1111/j.1600-9657.2006.00361.x.

[26] Westerman, B., Stringfellow, P.M., Eccleston, J.A. (2000) The effect on energy absorption of hard inserts in laminated EVA mouthguards. Aust. Dent. J. 45, pp. 21-23. DOI: 10.1111/j.1834-7819.2000.tb00237.x.

[27] Alexandra, M.O., Mihai, C.D.A.N., Marin, S., Ştefan, S. (2018) Low-velocity impact testing of foam core sandwich panels. J. Engineering Sciences and Innovation 3, pp. 93-106.

[28] Mcglumphy, K.C., Mendel, D.A., Yilmaz, B., Seidt, J.D. (2014) Pilot study of 3D image correlation photogrammetry to assess strain and deformation of mouthguard materials. Dent. Traumatol. 30, pp. 236-239. DOI: 10.1111/edt.12076.

[29] Liang, K., Carmone, S., Brambilla, D., Leroux, J.-C. (2018) Applied Sciences and Engineering 3D printing of a wearable personalized oral delivery device: A first-in-human study. Sci. Adv. 4, eaat2544. DOI: 10.1126/sciadv.aat2544. 